\title{
Spatial heterogeneity of plant species on the windward slope of active sand dunes in a semi-arid region of China
}

\author{
DeMing JIANG ${ }^{1 *}$, ChunPing MIAO ${ }^{1,2}$, XueHua $\mathrm{LI}^{1}$, XiaoLan $\mathrm{LI}^{3}, \mathrm{ALAMUSA}^{1}$, QuanLai ZHOU ${ }^{1}$ \\ ${ }^{1}$ Institute of Applied Ecology, Chinese Academy of Sciences, Shenyang 110016, China; \\ ${ }^{2}$ Graduate University of Chinese Academy of Sciences, Beijing 100049, China; \\ ${ }^{3}$ Xinjiang Academy of Agricultural and Reclamation Sciences, Shihezi 832000, China
}

\begin{abstract}
Species richness and abundance are two important species diversity variables that have attracted particular attention because of their significance in determining present and future species composition conditions. This paper aims to explain the qualitative and quantitative relationships between species diversity pattern and grain size (i.e. size of the sampling unit), and species diversity pattern and sampling area, and to analyze species diversity variability on active sand dunes in the Horqin Sandy Land, northeastern Inner Mongolia, China. A $50 \mathrm{~m} \times 50 \mathrm{~m}$ sampling plot was selected on the windward slope, where the dominant species was annual herb Agriophyllum squarrosum. Species composition and abundance at five grain sizes were recorded, and the species-area curves were produced for thirteen grain sizes. The range of values for species abundance tended to increase with increasing grain size in the study area, whereas, generally, species richness did not follow this rule because of poor species richness on the windward slope of active sand dunes. However, the homogeneity of species richness increased significantly. With the increase in sampling area, species abundance increased linearly, but richness increased logarithmically. Furthermore, variograms showed that species diversity on the windward slope of active sand dunes was weakly anisotropic and the distribution pattern was random, according to the Moran Coefficient. The results also showed that species richness was low, with a random distribution pattern. This conflicts with the results of previous studies that showed spatial aggregation in lower richness in a sampling area within a community and inferred that the physical processes play a more important role in species diversity than distribution pattern on active sand dunes. Further research into different diversity patterns and mechanisms between active sand dunes and interdune lowlands should be conducted to better understand biodiversity conservation in sand dune fields.
\end{abstract}

Keywords: abundance; richness; grain size; species-area curve; variogram; Horqin Sandy Land

Citation: DeMing JIANG, ChunPing MIAO, XueHua LI, XiaoLan LI, ALAMUSA, QuanLai ZHOU. 2013. Spatial heterogeneity of plant species on the windward slope of active sand dunes in a semi-arid region of China. Journal of Arid Land, 5(1): 80-88.

Species diversity generally refers to the spatial or temporal richness, abundance or heterogeneity of species in a given area. It has attracted particular attention, in large part because of its significance in helping determine the present conditions and likely future composition of species (He and Legendre, 2002; Wang et al., 2008). Ecologists have expended much effort to establish and qualify the underlying biological or physical processes that influence species diversity, e.g. extinction, migration, colonization, niche segregation, competition, predation, environmental disturbances, and historical dynamics (He and Legendre, 2002).

Active sand dunes, formed by land degradation, are characterized by extreme temperatures and low nutrient levels (Olsson and Wilhelmsson, 2000), as well as low water-holding and base exchange capacities (Vardavakis, 1992). In contrast to the relatively stable nature of soils, active sand dunes are unfavorable for the survival of most species except some psammophytes due to their unstable substrate ecosystems (Zhu et al.,

*Corresponding author: DeMing JIANG (E-mail: jiangdeming@iae.ac.cn) 
1998; Kent et al., 2005; Ma and Liu, 2008). Vegetation is a sensitive indicator of the conditions (health) of a landscape, particularly in arid and semiarid areas (Chen et al., 2002). Thus, vegetation restoration has been practiced for centuries to control sand movement and reduce the hazardous effects of active sand dunes. In particular, the dynamic patterns of vegetation on the windward slope of active sand dunes have been studied to supply a better scientific understanding of succession within ecosystems (Zhu et al., 1998; Foster and Tilman, 2000; Wall et al., 2002). Species diversity is the critical attribute of plant communities and is of considerable significance in the study of succession, since variations in species diversity are presumably correlated with the stability of various biotic and abiotic components within ecosystems (Leigh Jr, 1965; MacArthur, 1995).

The relationship between spatial scale and patterns of plant diversity, studied by comparing local and regional diversity or patch and local diversity, is currently a highly debated topic in ecology and macroecology (Caley and Schluter, 1997; Srivastava, 1999; Crist et al., 2003; Rahbek, 2005). An exploration of how diversity pattern changes with spatial scale is needed for the extrapolation of small and even broaderscale phenomena.

The concept of spatial scale refers to two main components of the sampling design: (1) Grain size, or the size of the sampling unit, which is the surface area of a place in which any particular measurement is made; and (2) The extent of the total area for sampling, or field size (Turner et al., 1989; Wiens, 1989; Hulme, 2008). Grain and extent define the upper and lower limits of resolution of a study. Inference in any study is limited by its grain and extent. Comprehension of how grain and extent affect our perception of ecological phenomena is fundamental to an understanding of scaling effects (He et al., 1994; Dungan et al., 2002). Results may differ when the same data are examined at varying grains and extent (He et al., 1994; Dungan et al., 2002; Hess et al., 2006). He et al. (1994) concluded that the effect of scaling on measures of biological diversity is non-linear; heterogeneity increased with the size of extent. Garson et al. (2002) correlated avian species richness with threatened and endangered species richness in southern Quebec and found that the degree of correlation increased with increasing grain size. According to Rosenzweig (1995), the 'speciesarea pattern' comprises four different SARs (1. species-area curves among tiny pieces of single biota, 2 . species-area curves among larger pieces of single biota, 3. species-area curves among islands of one archipelago, and 4 . species-area curves among areas that have had separate evolutionary histories), since the processes determining species richness are scale dependent (Whittaker, 2000; Crawley and Harral, 2001; White et al., 2010; Triantis et al., 2012). However, the scale effect of species diversity patterns on the windward slope of active sand dunes is unknown.

Moreover, the semi-variogram, a geostatistic method that stratifies the variance in a data set by at least one spatial or temporal dimension, is a useful tool for identifying both the structure of variability for that dimension and for qualifying the scale of autocorrelation (Rossi et al., 1992; Jackson and Caldwell, 1993). Semi-variograms and related measures (e.g. co-variogram and correlogram) may be applied to linear or two-dimensional data sets, and traditionally have been used for two broad purposes: the quantification of the scale of variability exhibited by natural patterns of resource distribution (i.e. soil type, habitat type, and biomass), and the identification of the spatial or temporal scale at which a sampled variable exhibits maximum variance (Meisel and Turner, 1998).

The aim of this study was to observe the effect of scale change on observed spatial patterns of species diversity on active sand dunes in a semi-arid region of China. We addressed the following questions: (1) How does species diversity change with grain size and sampling areas, and what mathematical function best describes the species-area relationship? (2) How does species diversity present itself on active sand dunes; is it isotropic or anisotropic?

\section{Materials and methods}

\subsection{Study area and field sampling}

The study was conducted at the Wulanaodu Experimental Station for Desertified Regions, Chinese Academy of Sciences, located in the western Horqin Sandy Land, northeastern Inner Mongolia, China (119 $39^{\prime}-$ $120^{\circ} 02^{\prime} \mathrm{E}, 42^{\circ} 29^{\prime}-43^{\circ} 06^{\prime} \mathrm{N}, 480 \mathrm{~m}$ asl). The area has a 
semiarid continental monsoon climate. According to the data from 1957-2002, the annual average temperature is $6.3^{\circ} \mathrm{C}$. The lowest average temperature, $-14.0^{\circ} \mathrm{C}$, occurs in January and the highest, $23.0^{\circ} \mathrm{C}$, occurs in July. The average annual precipitation is 284 $\mathrm{mm}, 70 \%$ occurring in the summer (June-August). The annual mean wind velocity is $4.4 \mathrm{~m} / \mathrm{s}$, and the number of gale days (wind speed $>17 \mathrm{~m} / \mathrm{s}$ ) is $21-80$ days. Since the 1950s, this region has undergone severe land degradation or desertification due to overgrazing, over-intensive farming and vegetation clearing, resulting in alternative landscapes of active, semi-active and stabilized sand dunes. Active sand dunes are especially widely distributed in this area, with movement rates of 5-7 m/a (Liu et al., 2006). The environments of active sand dunes are usually characterized by drought, strong wind erosion and sand burial (Yan et al., 2005).

In September 2011, a $50 \mathrm{~m} \times 50 \mathrm{~m}$ sampling plot was selected on the windward slope (reaching to the dune crest) of an active sand dune, with a 15-m vertical distance between the lower and upper sides of the plot. The sampling plot was divided into 2,500 quadrats $(1 \mathrm{~m} \times 1 \mathrm{~m})$. Species composition and abundance were recorded in each quadrat. For bunchgrasses (e.g. Setaria viridis), we counted the number of culm clusters to get the abundance. For species with discrete individuals (e.g. Agriophyllum squarrosum), the number of individuals was counted as the abundance.

\subsection{Data analysis}

In this paper, the diversity refers to richness and abundance. Richness is defined as the number of species in the study area and abundance as the number of all individuals.

For the purpose of examining the correlations of diversity patterns with varying grains (size of the sampling unit), the $50 \mathrm{~m} \times 50 \mathrm{~m}$ sampling plot was divided into a grid system using five grain sizes: $1 \mathrm{~m} \times 1$ $\mathrm{m}$ (2,500 quadrats), $2 \mathrm{~m} \times 2 \mathrm{~m}$ (625), $5 \mathrm{~m} \times 5 \mathrm{~m}(100)$, $10 \mathrm{~m} \times 10 \mathrm{~m}(25)$, and $25 \mathrm{~m} \times 25 \mathrm{~m}$ (4). Species abundance and richness in each quadrat were counted for each grain size, and species abundance and richness maps for the five grain sizes were then produced by ArcGIS (Version 9.3). In addition, the relationships between diversity patterns and 13 area sizes $(1 \mathrm{~m} \times 1 \mathrm{~m}$, $2 \mathrm{~m} \times 2 \mathrm{~m}, 4 \mathrm{~m} \times 4 \mathrm{~m}, 5 \mathrm{~m} \times 5 \mathrm{~m}, 8 \mathrm{~m} \times 8 \mathrm{~m}, 10 \mathrm{~m} \times 10 \mathrm{~m}$, $12 \mathrm{~m} \times 12 \mathrm{~m}, 16 \mathrm{~m} \times 16 \mathrm{~m}, 20 \mathrm{~m} \times 20 \mathrm{~m}, 25 \mathrm{~m} \times 25 \mathrm{~m}, 30$ $\mathrm{m} \times 30 \mathrm{~m}, 40 \mathrm{~m} \times 40 \mathrm{~m}$ and $50 \mathrm{~m} \times 50 \mathrm{~m}$ ) were developed using exponential equations, power equations and logarithmic functions (Microsoft Excel 2007). Significance tests were performed using the Statistics Analysis System (SAS software package).

Semi-variance, calculated using GS+ (Gamma design software, version 9.0), was used to detect the spatial variability of species diversity because semi-variance analysis (Meisel and Turner 1998; Wang et al., 2008) examines the contribution to the total sample variance made by the average variance of all pairs of points that are separated by a specific lag distance. The standard equation for the semi-variogram is:

$$
\gamma(h)=\frac{1}{2 N(h)} \sum_{i=1}^{N(h)}\left(x_{i}-y_{i}\right)^{2} .
$$

Where, $\chi(h)$ is semi-variance at lag distance $\mathrm{h} ; N(h)$ is number of pairs separated by distance $\mathrm{h} ; x_{i}$ is the value at the start, or tail, of the pair; $y_{i}$ is value at the end, or head, of the pair. Semi-variograms, which plot semi-variance against lag distance, typically increase from a theoretical Y-intercept of zero (the 'nugget'), and level off at the maximum semi-variance (the 'sill'), which occurs at and beyond a particular lag distance (the 'range'). The range identifies the distance beyond which pairs of objects no longer exhibit spatial autocorrelation. The ratio of the nugget effect to the sill is referred to as the relative nugget effect; it can be used to evaluate sampling error and small-scale spatial effect. To determine the strength of anisotropy, variograms of richness and abundance were computed in four geographic directions: $0^{\circ}$ (west-east, WE), $90^{\circ}$ (north-south, NS), $45^{\circ}$ (SW-NE) and $135^{\circ}$ (SE-NW). We then compared the multi-scale spatial autocorrelation of the analyzed variables by calculating the Moran Coefficient (Moran's I, by GS+ Gamma design software, version 9.0):

$$
I(h)=N(h) \sum \sum Z_{i} Z_{i+h} / \sum Z_{i+h}^{2} .
$$

Where, $I(h)$ is autocorrelation for interval distance class $h, Z_{i}$ is the measured sample value at point $I$, and $Z_{i+h}$ is the measured sample value at point $i+h$. 


\section{Results}

The dominant species on the active sand dune is annual herb A. squarrosum, with the rare shrub Salix gordejevii, annual herb Setaria viridis, semi-shrub Artemisia wudanica and annual herb Corispermum

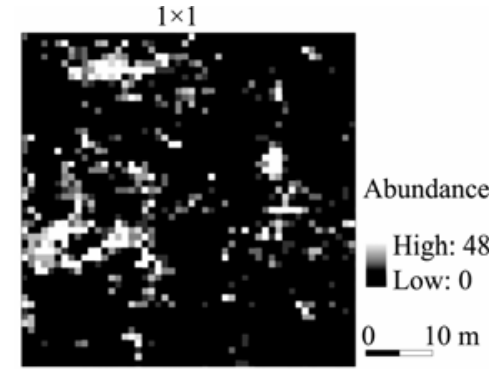

$2 \times 2$
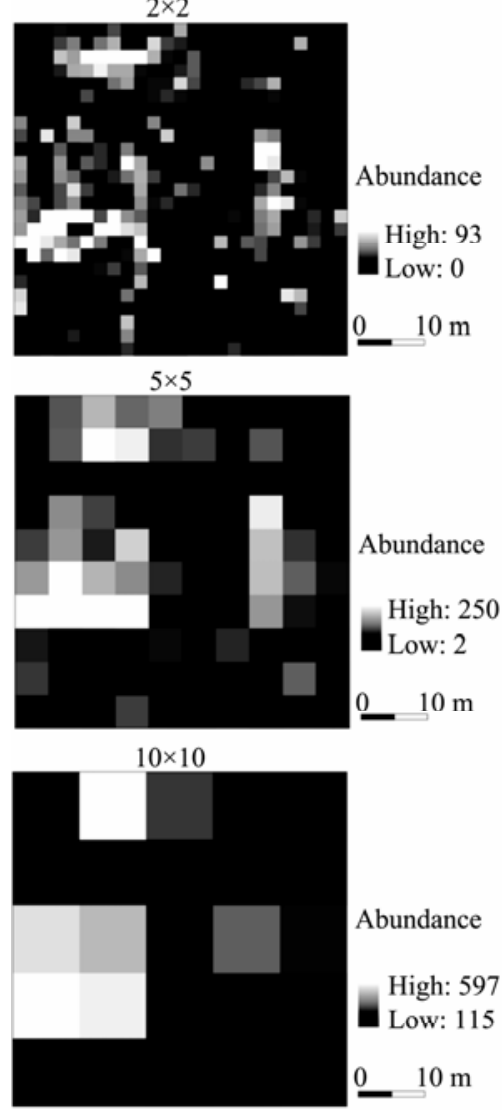

$25 \times 25$

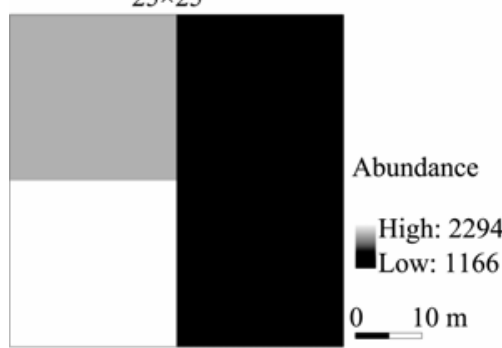

candelabrum also present.

\subsection{Diversity patterns varying with grain and extent}

Species abundance and richness had low values at fine spatial scales and high values at coarse spatial scales (Fig. 1). The species diversity had a significant spatial
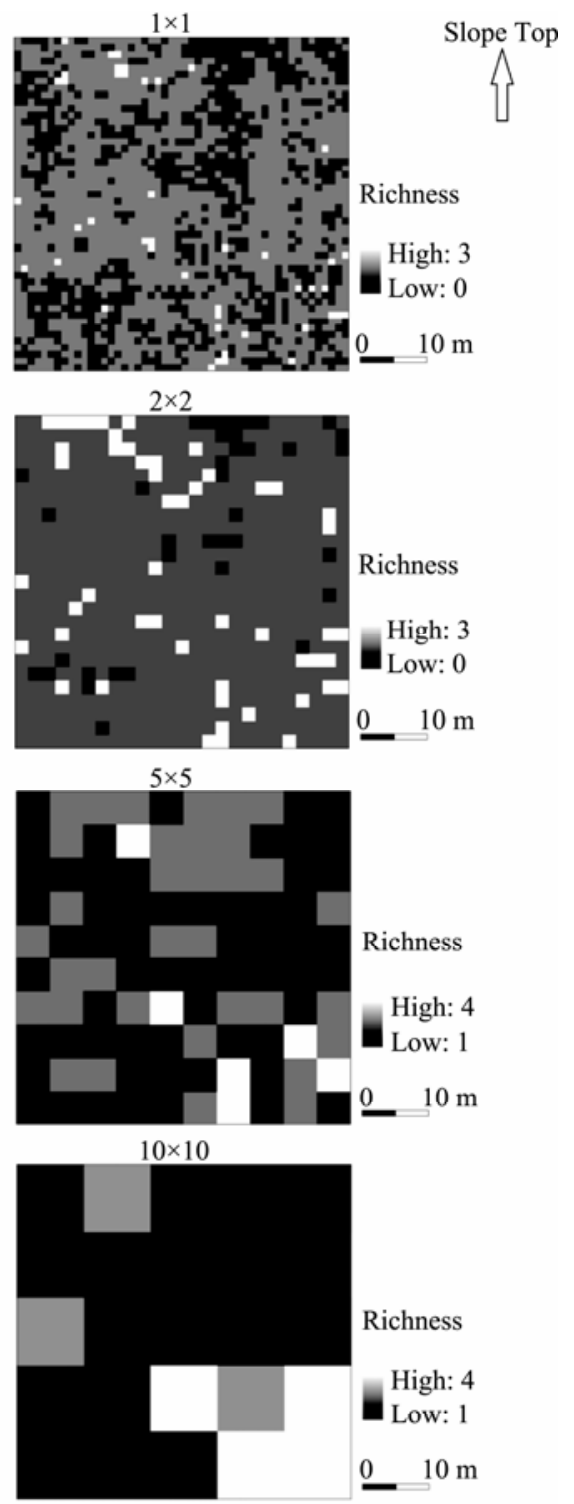

$25 \times 25$

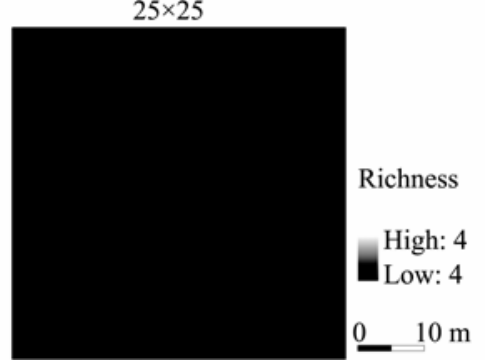

Fig. 1 Maps of species abundance and richness at five grain sizes $(1 \mathrm{~m} \times 1 \mathrm{~m}, 2 \mathrm{~m} \times 2 \mathrm{~m}, 5 \mathrm{~m} \times 5 \mathrm{~m}, 10 \mathrm{~m} \times 10 \mathrm{~m}$, and $25 \mathrm{~m} \times 25 \mathrm{~m})$ 
heterogeneity at fine scales, but the homogeneity increased with the increasing spatial scales. Ranges for species richness were especially poor, with value ranges from 0 to 3 for both $1 \mathrm{~m} \times 1 \mathrm{~m}$ and $2 \mathrm{~m} \times 2 \mathrm{~m}$ and the high value at coarse grains only 4 . The values of abundance increased significantly with increasing grain sizes. In the sampling site, species-area curves showed a close relationship, i.e. a definitely linear model for abundance-area $(y=2.9017 x+46.636)$ and a logarithmic model for richness-area $(y=0.5886 \ln (x)$ 0.0559) (Fig. 2).

\subsection{Spatial variability of diversity}

The semi-variance analysis of species abundance and

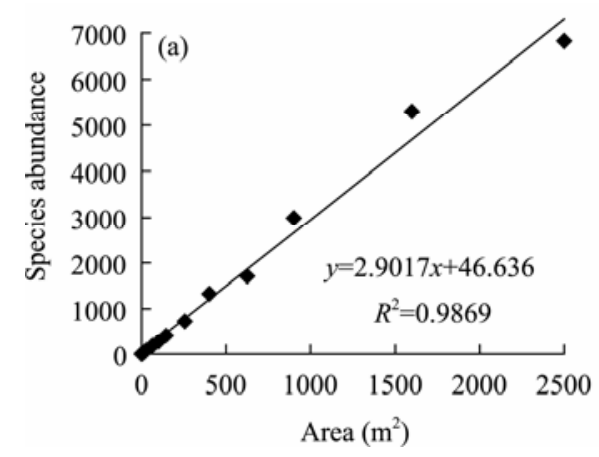

richness showed that there were relatively high degrees of spatial heterogeneity for both measurements (Fig. 3). For abundance, the nugget $\left(\mathrm{C}_{0}\right)$ variance was 3.04 and sill $\left(\mathrm{C}_{0}+\mathrm{C}\right)$ was 18.76 (Table 1). The nugget variance and sill indicated that the abundance showed high heterogeneity, of which $16 \%$ came from random factors and $84 \%$ from spatial autocorrelation. However, the nugget variance and sill values for species richness were 0.023 and 0.248 , respectively, and the heterogeneity of this poor richness was significantly lower than that of abundance. For this poor richness, $9 \%$ of the spatial heterogeneity came from sill and $91 \%$ came from spatial autocorrelation.

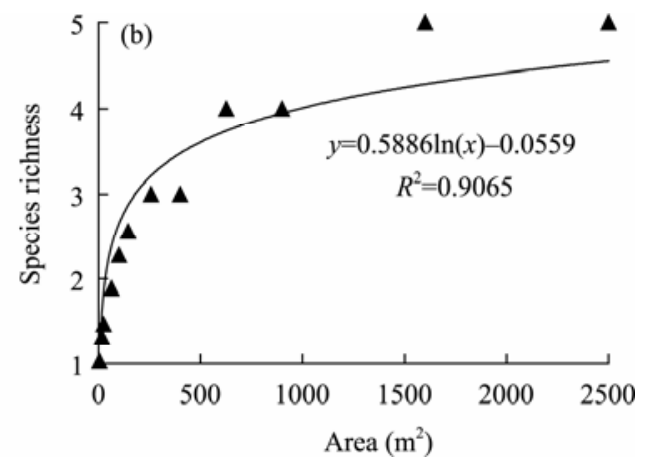

Fig. 2 Species abundance-area curve (a) and species richness-area curve (b) $(P<0.0001)$
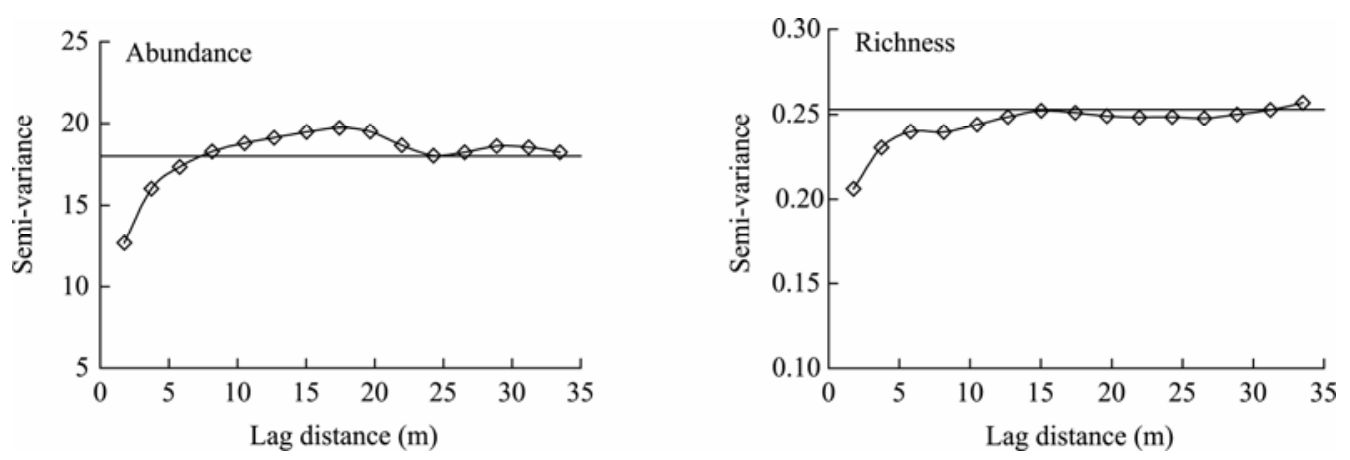

Fig. 3 Variograms of species abundance and richness under isotropic conditions; the horizontal lines indicate the overall variance of the variables in the plot.

Table 1 The models and parameters for semi-variograms of species abundance and richness under isotropy and anisotropy

\begin{tabular}{rccrccccccc}
\hline \multicolumn{2}{c}{ Index } & Models & \multicolumn{1}{c}{$\mathrm{C}_{0}$} & \multicolumn{1}{c}{$\mathrm{C}_{0}+\mathrm{C}$} & $\mathrm{C}_{0} /\left(\mathrm{C}_{0}+\mathrm{C}\right)$ & \multicolumn{1}{c}{$\mathrm{A}_{0}$} & $\mathrm{~A}_{\text {Major }}$ & $\mathrm{A}_{\text {Minor }}$ & $\mathrm{RSS}$ & $R^{2}$ \\
\hline \multirow{2}{*}{ Abundance } & Isotropic & Exponential & 3.040 & 18.760 & 16.200 & 2.020 & - & - & 3.920 & 0.911 \\
& Anisotropic & Linear & 16.450 & 42.330 & 38.860 & - & 317.800 & 238.600 & 252.000 & 0.334 \\
\multirow{3}{*}{ Richness } & Isotropic & Exponential & 0.023 & 0.248 & 9.270 & 1.120 & - & - & 0.070 & 0.825 \\
& Anisotropic & Linear & 0.225 & 0.502 & 44.820 & - & 248.900 & 248.800 & 0.352 & 0.440 \\
\hline
\end{tabular}


The variograms of abundance showed some anisotropy because semi-variances increased gradually in the $0^{\circ}$ and $135^{\circ}$ directions, whereas a unimodal peak appeared in each of the $45^{\circ}$ and $90^{\circ}$ directions (Fig. 4). Moreover, the semi-variances of abundance showed a rapid increase at small distance classes, which indicated that spatial structure is mainly characterized by random variation. The anisotropy of species abundance was mainly shown zonally because the differences of nugget, sill and range between the $0^{\circ}$ and $90^{\circ}$ directions were larger than those between the $45^{\circ}$ and $135^{\circ}$ directions. The semi-variances for species richness were not equal in the four directions, but the differences were not significant because of the poor species richness on the active sand dune. The nugget effects on species richness in the four directions were $48 \%$, higher than on abundance in the four directions.

Considering the fact that the diversity was weakly anisotropic, we adopted Moran's I Coefficient to analyze the diversity patterns in a further step. Moran's I scalograms (Fig. 5) showed that the autocorrelation of species abundance was positive at the grain size of $<13 \mathrm{~m}$, whereas the autocorrelation of richness was positive at the grain size of $<11 \mathrm{~m}$. Moran's I scalograms for both abundance and richness decreased
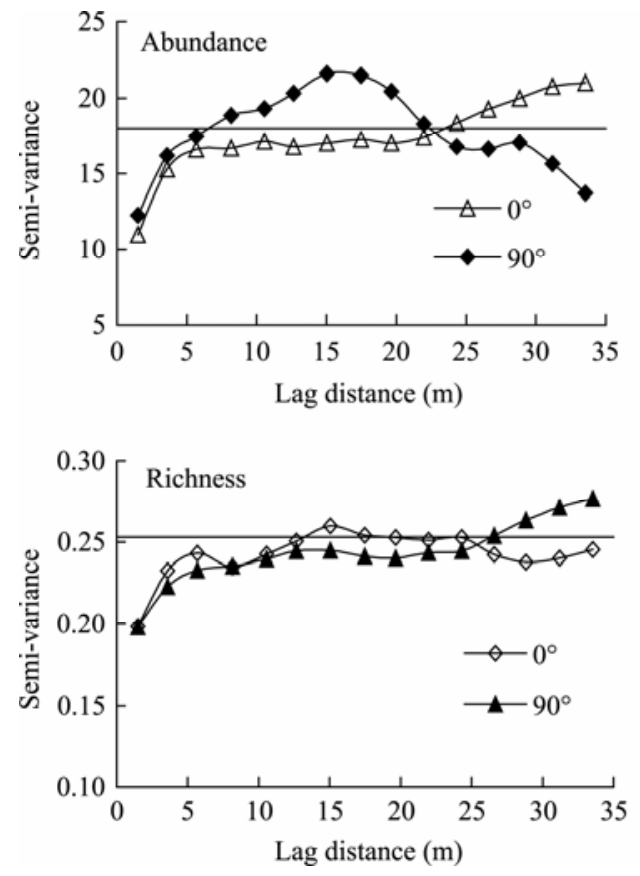

rapidly at finer scales, and then varied from positive through zero to negative circularly. This inferred that the critical scales to include maximum abundance and richness were $13 \mathrm{~m}$ and $11 \mathrm{~m}$, respectively, and that vegetation was distributed randomly on the active sand dune.

\section{Discussion and conclusions}

Changing the meaning of the scales from grain to extent may have important qualitative and quantitative effects on how measurements change across scales (Turner et al., 1989). The range of species abundance increased from 48 to $93,248,482$ and 1,128 successively as the grain sizes increased. However, species richness did not follow this rule, largely because of the poor species richness on the active sand dune. Meentemeyer and Box (1987) concluded that the detailed information may be lost with increasing area, and decreasing area may reveal new details. This is true for poor species richness because homogeneity appeared as the grain size increased to $25 \mathrm{~m} \times 25 \mathrm{~m}$, whereas heterogeneity appeared as the grain size decreased. He et al. (1994) found that more precise estimates of abundance or density could be obtained from
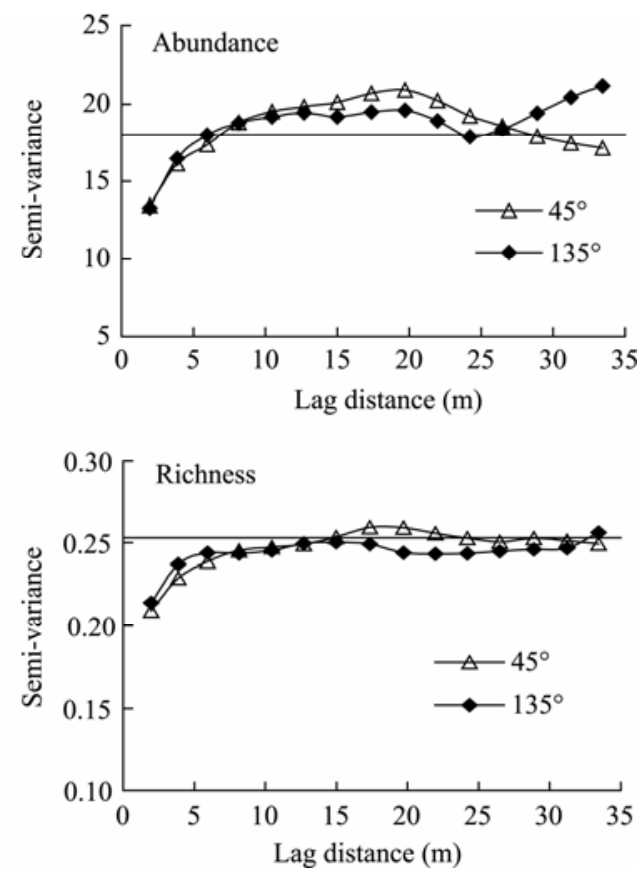

Fig. 4 Variograms of species abundance and richness in four geographic directions: $0^{\circ}$ (west-east, WE), $90^{\circ}$ (north-south, NS), $45^{\circ}$ $(\mathrm{SW}-\mathrm{NE})$ and $135^{\circ}$ (SE-NW); the horizontal lines indicate the overall variance of the variables in the plot. 

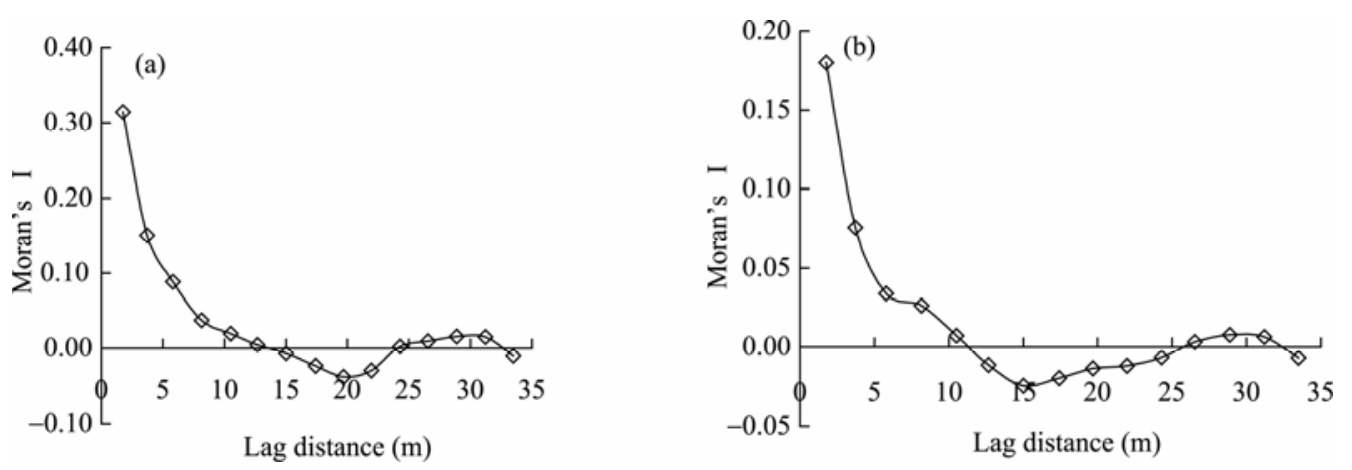

Fig. 5 Moran's I scalograms of species abundance (a) and richness (b)

a large grain size, while more precise estimates of richness came from small grain sizes. However, these two variables of species diversity changed differently because they have different spatial properties, i.e. abundance is additive but richness is non-additive when aggregated across sampling areas (He and Legendre, 1996; He and Legendre, 2002; Wang et al., 2008).

The studies of species-area relationship have long been focused on the shape of the relationship, its interpretation, and the mechanism of explaining the proposed form (Connor and McCoy, 1979; McGuinness, 1984). Many researchers have attempted mathematically to derive species-area curves on the basis of the assumption of a linear relationship between the number of individuals and the area (Preston, 1960, 1962a, b; Engen, 1977; Wright, 1988). Our study showed a result consistent with this assumption, i.e. species abundance increased with increasing sampling area in a linear function. However, species richness increased in a logarithmic function. Williams $(1943,1964)$ proposed a hypothesis of habitat diversity to explain the correlation between species and area, i.e. with the increase of sampling area, a greater diversity of environments is included, and so the number of species increases. Generally, the environment is never homogeneous (He and Legendre, 1996). Even for the relatively homogeneous active sand dune, heterogeneity is still detectable. Actually, both the equilibrium hypothesis and the habitat diversity hypothesis could explain the power model (Williams, 1943; MacArthur and Wilson, 1963). The linear function and logarithmic functions indicated that species diversity patterns on the active sand dune are under non-equilibrium conditions. In this situation, the conditions that increase the growth rates of competing species could result in a decline in species diversity, and the conditions that reduce the growth rates could maintain or allow an increase in diversity (Huston, 1979).

Variograms of abundance and richness on the active sand dune in the Horqin Sandy Land showed anisotropy between the four directions was not significant, and that isotropy for richness is higher than that for abundance. The Intermediate Disturbance Hypothesis states that higher species diversity occurs at intermediate levels of disturbance because species coexistence is maintained at a non-equilibrium state and no strong competitor can dominate completely (Connell, 1978). However, due to the semi-arid climate and relatively severe sand burial, species diversity on the active sand dune is very low, which may cause the spatial variability of diversity to be weakly anisotropic. The relatively low nugget to sill value $\left(\mathrm{C}_{0} /\left(\mathrm{C}_{0}+\mathrm{C}\right)\right)$ for abundance and richness in isotropy especially indicated that the spatial heterogeneity mainly came from spatial autocorrelation.

Species abundance and richness in an area greatly depends on the distributional patterns of species (Cawley, 1997; Ney-Nifle and Mangel, 1999). If a species is aggregated, the probability of presence of the species in a sampling area should be less than that under random distribution, and the higher the aggregation, the smaller the probability of presence. Moreover, species richness in a sampling area consistently decreases with the intensity of spatial aggregation of the species, and spatial regularity of species distribution promotes species richness in a sampling area; in 
other words, spatial aggregation resulted in lower richness in a sampling area within a community (He and Legendre, 2002). However, the species richness on the active sand dune is low since the distribution pattern is random rather than aggregated (Fig. 5). Consequently, the physical processes play a more important role in species diversity than the distribution pattern because species diversity on the active sand dune could also arise from many physical processes, such as the soil moisture, wind erosion, soil seed bank and low nutrient levels (Olsson and Wilhelmsson, 2000; Tsoar, 2005; Yu et al., 2008; Komac et al., 2011). Zhang et al. (2005) concluded that the primary difficulties for vegetation development on active sand dunes were the extremely barren soil and wind erosion which limited plant growth and prevented seedling establishment.

Actually, the plant diversity on the active sand dune is very much lower than in any other ecosystem. The aim of biodiversity conservation on the active sand dune is to protect the endemic plants and keep species richness and abundance increasing (Liu and Ma, 2008). Zhang et al. (2004) compared different measures of stabilizing active sand dunes and concluded that planting of endemic species is the most effective measure of vegetation restoration from an ecological viewpoint. Moreover, Liu and Ma (2008) suggested that biodiversity conservation on active sand dunes requires the sand dune and the interdune lowland be regarded as a unified landscape unit, and to explore the impacts of disturbances and habitat fragmentation on plant biodiversity of the whole sand dune ecosystem. Consequently, further research about different diversity patterns and mechanisms between active sand dune and interdune lowland should be conducted in future studies.

\section{Acknowledgements}

This work was funded by the National Natural Science Foundation of China (41071187) and the State Forestry Administration Industry Special Project (201004023).

\section{References}

Caley M J, Schluter D. 1997. The relationship between local and regional diversity. Ecology, 78: 70-80.
Chen Y F, Yu F H, Dong M. 2002. Scale-dependent spatial heterogeneity of vegetation in $\mathrm{Mu}$ Us sandy land, a semi-arid area of China. Plant Ecology, 162: 135-142.

Connell J H. 1978. Diversity in tropical rain forests and coral reefs. Science, 199: 1302-1310.

Connor E F, McCoy E D. 1979. The statistics and biology of the species-area relationship. The American Naturalist, 113: 791-833.

Crawley M J. 1997. The structure of plant communities. In: Crawley M J. Plant Ecology. $2^{\text {nd }}$ ed. London: Oxford, 475-531.

Crawley M J, Harral J E. 2001. Scale dependence in plant biodiversity. Science, 291: 864-868.

Crist T O, Veech J A, Gering J C, et al. 2003. Partitioning species diversity across landscapes and regions: a hierarchical analysis of $\alpha$, $\beta$ and $\gamma$ diversity. The American Naturalist, 162: 734-743.

Dungan J L, Perry J N, Dale M R T, et al. 2002. A balance view of scale in spatial statistical analysis. Ecography, 25: 626-640.

Engen S. 1977. Exponential and logarithmic species-area curves. The American Naturalist, 111: 591-594.

Foster B L, Tilman D. 2000. Dynamic and static views of succession: testing the descriptive power of the chronosequence approach. Plant Ecology, 146: 1-10.

Garson J, Aggarwal A, Sarkar S. 2002. Birds as surrogates for biodiversity: an analysis of a data set from southern Québec. Journal of Biosciences, 27: 347-360.

He F L, Legendre P, Bellehumeur C, et al. 1994. Diversity pattern and spatial scale: a study of a tropical rain forest of Malaysia. Environmental and Ecological Statistics, 1: 265-286.

He F L, Legendre P. 1996. On species-area relations. The American Naturalist, 148: 719-737.

He F L, Legendre P. 2002. Species diversity patterns derived from species-area models. Ecology, 83: 1185-1198.

Hess G R, Bartel R A, Leidner A K, et al. 2006. Effectiveness of biodiversity indicators varies with extent, grain, and region. Biological Conservation, 132: 448-457.

Hulme P F. 2008. Contrasting alien and native plant species-area relationships: the importance of spatial grain and extent. Global Ecology and Biogeography, 17: 641-647.

Huston M. 1979. A general hypothesis of species diversity. The American Naturalist, 113: 81-101.

Jackson R B, Caldwell M M. 1993. Geostatistical patterns of soil heterogeneity around individual perennial plants. Journal of Ecology, 81: 683-692.

Kent M, Owen N W, Dale M P. 2005. Photosynthetic responses of plant communities to sand burial on the MacHair dune systems of the Outer Hebrides, Scotland. Annals of Botany, 95: 869-877.

Komac B, Alados C L, Bueno C G, et al. 2011. Spatial patterns of species distributions in grazed subalpine grasslands. Plant Ecology, 212: 519-529.

Leigh Jr E G. 1965. On the relation between the productivity, biomass, diversity and stability of a community. Proceedings of the National 
Academy of Sciences of the United States of America, 53: 777-783.

Liu Z M, Yan Q L, Baskin C C, et al. 2006. Burial of canopy-stored seeds in the annual psammophyte Agriophyllum squarrosum Moq. (Chenopodiaceae) and its ecological significance. Plant and Soil, 288: 71-80.

Liu Z M, Ma J L. 2008. Research progress on plant diversity conservation in sand dune areas. Chinese Journal of Applied Ecology, 19(1): 183-190.

Ma J L, Liu Z M. 2008. Spatiotemporal pattern of seed bank in the annual Psammophyte Agriophyllum squarrosum Moq. (Chenopodiaceae) on the active sand dunes of northeastern Inner Mongolia, China. Plant and Soil, 311: 97-107.

MacArthur R H, Wilson E O. 1963. An equilibrium theory of insular zoogeography. Evolution, 17: 373-387.

MacArthur R H. 1995. Fluctuations of animal populations, and a measure of community stability. Ecology, 36: 533-536.

McGuinness K A. 1984. Equations and explanations in the study of species-area curves. Biological Review, 59: 423-440.

Meentemeyer V, Box E O. 1987. Scale effects in landscape studies. In: Turner M G. Landscape Heterogeneity and Disturbance. New York: Springer-Verlag, 15-36.

Meisel J E, Turner M G. 1998. Scale detection in real and artificial landscapes using semivariance analysis. Landscape Ecology, 13: 347-362.

Ney-Nifle M, Mangel M. 1999. Species-area curves based on geographical range and occupancy. Journal of Theoretical Biology, 196: 327-342.

Olsson P A, Wilhelmsson P. 2000. The growth of external AM fungal mycelium in sand dunes and in experimental systems. Plant and Soil, 226: 161-169.

Preston F W. 1960. Time and space and the variation of species. Ecology, 41: 611-627.

Preston F W. 1962a. The canonical distribution of commonness and rarity: Part I. Ecology, 43: 185-215.

Preston F W. 1962b. The canonical distribution of commonness and rarity: Part II. Ecology, 43: 410-432.

Rahbek C. 2005. The role of spatial scale and the perception of large-scale species richness patterns. Ecology Letters, 8: 224-239.

Rosenzweig M L. 1995. Species Diversity in Space and Time. England: Cambridge University Press.

Rossi R E, Mulla D J, Journel A G, et al. 1992. Geostatistical tools for modeling and interpreting ecological spatial dependence. Ecological Monographs, 62: 277-314.

Srivastava D S. 1999. Using local-regional richness plots to test for species saturation: pitfalls and potentials. Journal of Animal Ecology, 68: 1-16.
Triantis K A, Guilhaumon F, Whittaker R J. 2012. The island species-area relationship: biology and statistics. Journal of Biogeography, 39: 215-231.

Tsoar H. 2005. Sand dunes mobility and stability in relation to climate. Physica A: Statistical Mechanics and its Applications, 357: 50-56.

Turner M G, O'Neill R V, Gardner R H, et al. 1989. Effects of changing spatial scale on the analysis of landscape pattern. Landscape Ecology, 3: 153-162.

Vardavakis E. 1992. Mycorrhizal endogonaceae and their seasonal variations in a Greek sand dune. Pedobiologia, 36: 373-382.

Wall J W, Skene K R, Neilson R. 2002. Nematode community and trophic structure along a sand dune succession. Biology and Fertility of Soils, 35: 293-301.

Wang X G, Hao Z Q, Ye J, et al. 2008. Spatial variation of species diversity across scales in an old-growth temperate forest of China. Ecological Research, 23: 709-717.

White E P, Ernest S K M, Adler P B, et al. 2010. Integrating spatial and temporal approaches to understanding species richness. Philosophical Transactions of the Royal Society B: Biological Sciences, 365: 3633-3643.

Whittaker R J. 2000. Scale, succession and complexity in island biogeography: are we asking the right questions? Global Ecology and Biogeography, 9: 75-85.

Wiens J A. 1989. Spatial scaling in ecology. Functional Ecology, 3: 385-397.

Williams C B. 1943. Area and number of species. Nature, 152: 264-267.

Williams C B. 1964. Patterns in the Balance of Nature. New York: Academic Press.

Wright S J. 1988. Patterns of abundance and the form of the species-area relation. The American Naturalist, 131: 401-411.

Yan Q L, Liu Z M, Zhu J J, et al. 2005. Structure, pattern and mechanisms of formation of seed banks in sand dune systems in northeastern Inner Mongolia, China. Plant and Soil, 277: 175-184.

Yu F H, Wang N, He W M, et al. 2008. Adaptation of rhizome connections in drylands: increasing tolerance of clones to wind erosion. Annals of Botany, 102: 571-577.

Zhang J Y, Zhao H L, Zhang T H, et al. 2005. Community succession along a chronosequence of vegetation restoration on sand dunes in Horqin Sandy Land. Journal of Arid Environments, 62: 555-566.

Zhang T H, Zhao H L, Li S G, et al. 2004. A comparison of different measures for stabilizing moving sand dunes in the Horqin Sandy Land of Inner Mongolia, China. Journal of Arid Environments, 58: 203-214.

Zhu Z D, Zhao X L, Lin Y Q, et al. 1998. Sandy Land Rehabilitation Engineering. Beijing: China Environmental Science Press. 